\title{
Effect of Early Mobilization on the Decrease in Pain Intensity Among Post Cesarean Section Patients at Cirebon Hospital in 2019
}

\author{
$1^{\text {st }}$ Roheman \\ Lecture of Nursing Study Program \\ Medical Surgical Concentration \\ Health Science Higher Education \\ Cirebon \\ Cirebon, Indonesia \\ $4^{\text {th }}$ Masrifah \\ Lecture of Nursing Study Program \\ Medical Surgical Concentration \\ Health Science Higher Education \\ Cirebon \\ Cirebon, Indonesia
}

\author{
$2^{\text {nd }}$ Healthy Seventina \\ Lecture of Nursing Study Program \\ Medical Surgical Concentration \\ Health Science Higher Education \\ Cirebon \\ Cirebon, Indonesia \\ healthy.seventinasirait@gmail.com \\ $5^{\text {th }}$ Wike \\ Lecture of Nursing Study Program \\ Medical Surgical Concentration \\ Health Science Higher Education \\ Cirebon \\ Cirebon, Indonesia
}

\author{
$3^{\text {rd }}$ Mustopa \\ Lecture of Nursing Study Program \\ Medical Surgical Concentration \\ Health Science Higher Education \\ Cirebon \\ Cirebon, Indonesia
}

\begin{abstract}
A mother who gives birth to a baby with a Cesarean Section surgery usually experience pain. Early mobilization is one way to decrease pain intensity among post Cesarean Section patients. This study aims to determine the effect of early mobilization on the decrease in pain intensity among post Cesarean Section patients at Cirebon Hospital. The method used here was quasi-experimental (one group pretest-posttest design) using early mobilization intervention. The populations in this study were 46 patients. Data collection was carried out by observing pain scores among post Cesarean Section patients before intervention by using a predetermined observation sheet given to 31 patients in the Melati ward at Cirebon Hospital where samples were taken by accidental sampling. The observations were carried out before and after the intervention. The results showed that the mean score of pain among post Cesarean Section patients before intervention was 9,19 while the mean score of pain among patients with post Cesarean Section after intervention was 3.68. Thus, it could be concluded that there was a change or decrease in the mean of pain intensity among post Cesarean Section patients of 5.51. This showed that early mobilization could significantly decrease pain intensity among post Cesarean Section patients. Hypothesis test used using Wilcoxon, where $P$ Value obtained was 0.000 or $<0.05$, so that $\mathrm{HO}$ was rejected or Ha was accepted, or in other words there was an effect of early mobilization on the decrease in pain intensity among post Cesarean Section patients at Cirebon Hospital. Recommendation in this study was that nurses should implement early mobilization as an effort to decrease pain among post Cesarean Section patients in a non-pharmacological manner.
\end{abstract}

Keywords-Early Mobilization, Decrease, Pain Intensity, Post Cesarean

\section{INTRODUCTION}

Childbirth is the process of expulsion of contraception outcomes (fetus and uri) that have been at term or can live outside the uetrus through the birth canal or not through the birth canal, with help or without help.[1] Labor that is done by means of surgery performed by the medical team called Cesarean Section. In practice, Cesarean Section surgery is done by making incisions on the abdomen and uterus of pregnant women to help the childbirth process. WHO (World Health Organization) sets the average standard of Cesarean Section in a country of around 5$15 \%$ per 1,000 births in the world. The incidence of CS in Government hospitals are about $11 \%$, while in private hospitals it can be more than 30\%.[2] Based on National Center for Health Statistics (2016)[3] generally in Indonesia, the number of Cesarean Section surgery in government hospitals was around $20 \%-25 \%$ of total deliveries, while in private hospitals the number was very high at around $30 \%-80 \%$ of total deliveries. In Indonesia alone, the total number of Cesarean Section experienced a surge in 2011. In that year the total number of women undergoing Cesarean Section delivery reached $47.22 \%$. A year after in 2012 it decreased to $45.19 \%$, a year later it increased again and reached $47.13 \%$. In 2013 CS delivery rate decreased again and stood at $46.87 \%$, after which the increase fluctuated to $53.2 \%$ in $2014,51.59 \%$ in 2015 , and $53.68 \%$ in 2016.[4]. Early mobilization among post Cesarean Section patients should be implemented by following the existing stages. The stages of early mobilization begin in the first 6 hours after delivery. [5] At this stage the patient is recommended to immediately lie down while moving her arms, legs, and toes with constant movement. In addition to doing the movements as recommended above, the patient is recommended to position her body in a state tilted to the left or right after 6-10 hours. This process is carried out to prevent thrombosis and thromboembolism. In the continued process that is 24 hours after giving birth, it is recommended to the patient to learn to sit.[6]

After the patient can sit comfortly, the patient is then taught to stand up but by adjusting the condition of the 
patient's body. Based on a Preliminary Study conducted on January 3, 2019, there were 537 patients who gave birth by Cesarean Section in Melati ward at Cirebon hospital in 2016, in 2017 there were 521 patients and in 2018 there were 553 patients. According to the results of interviews conducted with the Head of Melati ward, post Cesarean Section patient would feel pain when the effect anesthesia disappeared and one non-pharmacological therapy which was generally applied to decrease the pain level of post Cesarean Section patients was early mobilization (McLeod, R 2015). However, therapy with movement patterns that require patients to tilt left and right can only be done after 24-hour treatment to prevent spinal trauma due to the use of spinal anesthesia. Based on the results of interviews conducted among post Cesarean Section patients, pain began to decrease after early mobilization. On the first day post Cesarean Section patients began to move sideways left and right. The patients began to learn to sit on the second day and on the third day the patients began to learn to get out of bed as well as learning to walk on their own.[6]

Methods

The study design was arranged in such a way that it can obtain answers to the study questions. This study used a quasi-experimental design since this design does not have strict restrictions on randomization and can control the threats of validity at the same time.[7]

This study used a one group pretest and posttest approach, the experiment was conducted in one group only without a comparison group. However, this study conducted the first observation (pretest) before the intervention and then the second observation (posttest) after the intervention that allowed the researcher to test the changes that occurred after the intervention.

The design form used here was as follows:

\begin{tabular}{|rcc|}
\hline Pretest & Intervention & Posttest \\
\hline 01 & $\mathrm{X}$ & 02 \\
\hline
\end{tabular}

Information

$\mathrm{X} \quad$ : Early mobilization intervention

01 : Pain scale among post Cesarean Section patients before intervention

02

: Pain scale among post Cesarean Section patients after intervention

At the pretest stage, all study respondents, namely post Cesarean Section patients were given early mobilization for 3 days, the level of pain was measured with an observation sheet. After early mobilization, the level of pain was measured again (posttest). Subsequently, statistical analysis was conducted to determine difference in pain intensity among post Cesarean Section patients before and after early mobilization. The populations in this study were post Cesarean Section patients at Cirebon Hospital in April 2019 as many as 46 patients. The sample is a portion taken from the whole object studied and is considered to represent the entire population. In nursing study, the sample criteria include the exclusion and inclusion criteria, and these criteria are used to determine whether or not the sample can be used. Sampling in this study used the Accidental Sampling technique, namely sampling by taking respondents or cases that exist or available. The size of the study sample was found through the following formula. [8]

\section{RESULTS}

TABLE 1. PAIN AMONG POST CESAREAN SECTION PATIENTS BEFORE INTERVENTION

\begin{tabular}{|c|c|}
\hline Pain Level & Number of patient \\
\hline No Pain & 0 \\
\hline Mild Pain & 0 \\
\hline Moderate Pain & 0 \\
\hline Severe Pain & 25 \\
\hline Very Severe Pain & 6 \\
\hline
\end{tabular}

Mean score of pain among post Cesarean Section patients before intervention was 9.19. As many as 25 patients complained of severe pain and 5 patients complained of feeling very severe pain. Pain scores among post Cesarean Section patients before intervention were measured on the first day. The researcher collected data on 31 respondents using instrument that was predetermined in this study.

TABLE 2. PAIN AMONG POST CESAREAN SECTION PATIENTS AFTER INTERVENTION

\begin{tabular}{|c|c|}
\hline Pain Level & Number of patient \\
\hline No Pain & 0 \\
\hline Mild Pain & 11 \\
\hline Moderate Pain & 20 \\
\hline Severe Pain & 0 \\
\hline Very Severe Pain & 0 \\
\hline
\end{tabular}

Mean score of pain among post Cesarean Section patients after intervention was 3.68. 11 patients complained of mild pain and 20 other patients complained of feeling moderate pain.

Pain scores among post Cesarean Section patients after intervention were measured on day 3 . Based on the data collection of 31 respondents, no respondents dropped out during the study, so the respondents involved before the intervention were the same as those involved after the intervention.

TABLE 3. DIFFERENCE IN MEAN TEST

\begin{tabular}{|l|l|}
\hline Score & Mean \\
\hline Mean score before intervention & 9.19 \\
\hline Mean score after intervention & 3.68 \\
\hline $\begin{array}{l}\text { Difference in mean score before } \\
\text { and after intervention }\end{array}$ & 5.51 \\
\hline
\end{tabular}

TABLE 4. NORMALITY TEST

\begin{tabular}{|c|c|c|c|}
\hline No & Score & P. Value & $\begin{array}{c}\text { Distribution } \\
\text { of Data }\end{array}$ \\
\hline \multirow{2}{*}{$\begin{array}{l}1 \\
2\end{array}$} & \multirow{2}{*}{$\begin{array}{l}\text { Pain level score before } \\
\text { intervention } \\
\text { Pain level score after } \\
\text { intervention }\end{array}$} & 0.000 & Not Normal \\
\hline & & 0.000 & Not Normal \\
\hline
\end{tabular}


Based on the results of the Shapiro Wilk test above, it was revealed that the data were not normally distributed. Then the next step was conducting a non-parametric test by using the Wilcoxon test.

TABLE 5. WILCOXON TEST

\begin{tabular}{|l|l|l|l|l|}
\hline No & Score & Mean & Z Score & P. Value \\
\hline 1 & $\begin{array}{l}\text { Mean score before } \\
\text { intervention }\end{array}$ & 9.19 & \multirow{2}{*}{-4.994} & 0.000 \\
\hline 2 & $\begin{array}{l}\text { Mean score after } \\
\text { intervention }\end{array}$ & 3.68 & & \\
\hline
\end{tabular}

\section{DISCUSSION}

Based on the results of the study, it was obtained a mean score of pain among post Cesarean Section patients before early mobilization of 9.19. If the researcher took an assumption that the score of 9.19 was more than the value of 5.00 as the middle value of the pain score with a scale of $0-10$, then the score could be categorized as high. Other study conducted found that the mean score of the effect of early mobilization on the changes in pain level among post Cesarean Section patients before intervention was 7.75 and the mean score of the effect of early mobilization on the changes in pain level among post Cesarean Section patients after intervention was 5.62 or in other words the score of the changes in the level of pain among post Cesarean Section patients before intervention was higher than the score of the changes in the level of pain among post Cesarean Section patients after intervention[9]

Based on the results of the study, it was obtained a mean score of pain among post Cesarean Section patients after being given early mobilization treatment of 3.68. The score decreased when compared with the pain score among post Cesarean Section patients before intervention. A decrease in the mean score of pain among post Cesarean Section patients after the intervention was also found in a previous study conducted by.....[10] It was also found that the mean score of pain levels among post Cesarean Section patients prior to early mobilization was 5.77 and after early mobilization it changed to 3.99 or it was said that there was a decrease in the level of pain among post Cesarean Section patients before and after early mobilization. Wilcoxon pretest and post test results obtained $\mathrm{Z}$ score $=-6.835$ with $\mathrm{P}$-value $=0.000$. Based on these results, it was decided that $\mathrm{H} 0$ was rejected, meaning that there was an effect of early mobilization on the intensity of pain among post Cesarean Section patients.[11]

Based on the three studies above, it can be concluded that the pain score among post Cesarean Section patients, the level of pain among post Cesarean Section patients and the level of pain among post-appendectomy surgery clients after the intervention was lower than the value of pain among post Cesarean Section patients, the level of pain among post Cesarean Section patients and the level of pain among post-appendectomy surgery clients before intervention. [12] The decrease in pain value and the level of pain among post-appendectomy surgery clients was evidenced after early mobilization. Based on the results of the current study it can be concluded that after being given early mobilization, post Cesarean Section patients showed a decrease in pain intensity, especially on the parts that experienced pain due to incision wound[13]

\section{CONCLUSIONS}

Based on the results of the study that has been conducted among 31 post Cesarean Section patients who experienced pain at Cirebon Hospital in 2019 for 15 days, the following conclusions were taken: The mean score of pain among post Cesarean Section patients before early mobilization was 9.19 which was categorized in severe pain, The mean score of pain among post Cesarean Section patients after early mobilization was 3.68 which was categorized in a moderate pain. There was a difference in the mean score of pain among post Cesarean Section patients before and after early mobilization with a $\mathrm{p}$ value of 0.000 , then $\mathrm{H} 0$ was rejected and $\mathrm{Ha}$ was accepted or in other words early mobilization had a significant effect on the reduction in pain intensity among post Cesarean Section patients. Early mobilization was shown to have an effect on the decrease in pain intensity among post Cesarean Section patients. Nurses should implement early mobilization as an effort to decrease pain among post Cesarean Section patients in a nonpharmacological manner.

\section{REFERENCES}

[1] Mutmainnah, Normal delivery \& newborns care. 2017

[2] WHO, "World Health organisation Nursing and midwifery," 2018 .

[3] National Center for Health Statistics. (2016, "National Center for Health Statistics. (2016, April 27). Retrieved from Centers for Disease Control and Prevention: http://www.cdc.gov/nchs/fastats/healthexpenditures.htm," 2016. [Online]. Available: http://www.cdc.gov/nchs/fastats/healthexpenditures.htm.

[4] K. K. R. Ministry of Health of the Republic of Indonesia, "Situation and Analysis of Diabetes. Jakarta: Data And Information Center.," 2014.

[5] Lavanya Pashikanti; Von Ah; "Improving Nurse Knowledge and Attitudes of Early Mobilization of the Postoperative Patient.," J. Adv. Nursing., 2017.

[6] et al Wilson RD, Caughey AB, Wood SL, "Guideline for antenatal and preoperative care in cesarean delivery: Enhanced Recovery after Surgery Society recommendations 2018," Am. J. Obs. Gynecol, p. 219, 2018.

[7] Sugiyono., Quantitative-qualitative research methodology. 2010.

[8] Nursalam., Nursing science study methods-practical approach. 2015 .

[9] et al. Guyatt GH, Oxman AD, Vist GE, "GRADE: an emerging consensus on rating quality of evidence and strength of recommendations.," J. Cochrane Database Syst, vol. 8, 2015.

[10] Handayani Sri, "Effect of early mobilization on pain intensity among post cesarean section patients at DR. Moewardi Hospital Surakarta.," J. Nurs., 2016.

[11] Elias KM., "Understanding enhanced recovery after surgery guidelines: An introductory approach.," J. Laparoendosc Adv Surg Tech A, vol. 27, no. 5, p. 871, 2017.

[12] P. Kaur, H., Kaur, S., \& Sikka, "A quasi-experimental study to assess the effectiveness of early ambulation in post-operative recovery among postcesarean mothers admitted in selected areas of nehru hospital.," Nurs. Midwifery Res. J., vol. 11, no. 1, pp. 33-44, 2015.

[13] B. Kalisch, B., Lee, S., \& Dabney, "Outcomes of inpatient mobilization: a literature review.," . Am. J. Med. Qual., vol. 4, no. 26, 2013. 